\title{
Association between known or strongly suspected malignant hyperthermia susceptibility and postoperative outcomes: an observational population-based study
}

\section{Association entre une susceptibilité connue ou fortement suspectée à l'hyperthermie maligne et l'évolution postopératoire : une étude observationnelle de population}

Philip M. Jones, MD, MSc • Britney N. Allen, MSc • Richard A. Cherry, MD • Luc Dubois, MD, MSc • Kelly N. Vogt, MD, MSc • Salimah Z. Shariff, PhD • Krista M. Bray Jenkyn, PhD • Sheila Riazi, MD, MSc • Duminda N. Wijeysundera, MD, PhD

Received: 7 June 2018/Revised: 13 August 2018/Accepted: 16 August 2018/Published online: 12 November 2018

(C) Canadian Anesthesiologists' Society 2018

\begin{abstract}
Purpose Whether current standards of care management for malignant hyperthermia (MH)-susceptible patients result in acceptable postoperative clinical outcomes at a population level is not known. Our objective was to determine if patients with susceptibility to $M H$ experienced similar outcomes as patients without MH susceptibility after surgery under general anesthesia.

Methods This was a retrospective, population-based cohort study from 1 April 2009 until 31 March 2016 in the Canadian province of Ontario. Participants were adults who underwent common in- or outpatient surgeries
\end{abstract}

Electronic supplementary material The online version of this article (https://doi.org/10.1007/s12630-018-1250-8) contains supplementary material, which is available to authorized users.

P. M. Jones, MD, MSc ( $\varangle)$

Department of Anesthesia \& Perioperative Medicine, University of Western Ontario, London, ON, Canada

e-mail: philip.jones@1hsc.on.ca

Department of Epidemiology \& Biostatistics, University of Western Ontario, London, ON, Canada

London Health Sciences Centre, University Hospital, Room C3110, 339 Windermere Rd, London, ON N6A 5A5, Canada

B. N. Allen, MScK. M. Bray Jenkyn, PhD Institute for Clinical Evaluative Sciences, Western Site (ICES Western), London, ON, Canada

R. A. Cherry, MD

Department of Anesthesia \& Perioperative Medicine, University of Western Ontario, London, ON, Canada under general anesthesia. The exposure studied was either known or strongly suspected MH susceptibility as determined by usage of a specific physician billing code. The primary outcome was a composite of all-cause death, hospital readmission, or major postoperative complications, all within 30 postoperative days. Separate analyses were employed, based on whether a patient had in- or outpatient surgery. Inverse probability of exposure weighting based on the propensity score was used to estimate adjusted exposure effects.

Results The cohort included 957,876 patients (583,254 inand 374,622 outpatients). There were 2,900 (0.3\%) patients with a known or strong suspicion of $\mathrm{MH}$ susceptibility. For inpatients, the primary outcome

L. Dubois, MD, MSc

Department of Surgery, University of Western Ontario, London, ON, Canada

K. N. Vogt, MD, MSc

Department of Epidemiology \& Biostatistics, University of Western Ontario, London, ON, Canada

Department of Surgery, University of Western Ontario, London, ON, Canada

S. Z. Shariff, $\mathrm{PhD}$

Institute for Clinical Evaluative Sciences, Western Site (ICES

Western), London, ON, Canada

Arthur Labatt School of Nursing, University of Western Ontario, London, ON, Canada 
occurred in 146,192 (25.1\%) of the non-MH-susceptible group and in 337 (20.1\%) of the MH-susceptible group (unadjusted risk difference [RD], $-5.0 \%$; 95\% confidence interval [CI], -6.9 to $-3.1 \% ; P<0.001)$. In outpatients, the primary outcome occurred in 9,146 (2.4\%) of the nonMH-susceptible group and in 32 (2.6\%) of the $\mathrm{MH}$ susceptible group (RD, 0.2\%; 95\% CI, -0.7 to $1.1 \% ; P=$ 0.72). After adjustment, $M H$ susceptibility was not associated with the primary outcome in either the inpatients (adjusted risk difference [aRD], 1.2\%; 95\% CI, -1.3 to $3.6 \% ; P=0.35$ ) or outpatients (aRD, $-0.1 \%$; 95\% CI -1.0 to $0.9 \%$; $P=0.90)$.

Conclusions Among adults in Ontario who underwent common surgeries under general anesthesia from 2009 to 2016, known or strongly suspected MH was not associated with a higher risk of adverse postoperative outcomes. These findings support the current standard of care management for $\mathrm{MH}$-susceptible patients.

\section{Résumé}

Objectif Nous ignorons si les normes actuelles de gestion des soins de patients susceptibles d'hyperthermie maligne (HM) aboutissent à des résultats cliniques postopératoires acceptables à l'échelle d'une population. Notre objectif a été de déterminer si des patients présentant une susceptibilité à l'HM présentaient une évolution comparable à celle des patients non connus susceptibles après chirurgie sous anesthésie générale.

Méthodes Il s'agissait d'une étude de cohorte rétrospective, basée sur une population de la province canadienne de l'Ontario allant du $1^{\text {er }}$ avril 2009 au

S. Riazi, MD, MSc

Department of Anesthesia and Pain Management, Toronto General Hospital, Toronto, ON, Canada

Department of Anesthesia, University of Toronto, Toronto, ON, Canada

D. N. Wijeysundera, MD, PhD

Department of Anesthesia and Pain Management, Toronto General Hospital, Toronto, ON, Canada

Department of Anesthesia, University of Toronto, Toronto, ON, Canada

Li Ka Shing Knowledge Institute of St. Michael's Hospital, Toronto, ON, Canada

Institute of Clinical Evaluative Sciences, Central Site (ICES Central), Toronto, ON, Canada

Institute of Health Policy Management and Evaluation, University of Toronto, Toronto, ON, Canada
31 mars 2016. Les participants étaient des adultes, hospitalisés ou ambulatoires, ayant subi des interventions sous anesthésie générale. L'exposition étudiée était une susceptibilité à l'HM connue ou fortement suspectée, déterminée par l'utilisation d'un code de facturation spécifique des médecins. Le critère d'évaluation principal était un critère composite incluant les décès toutes causes confondues, les réadmissions hospitalières ou les complications postopératoires majeures qui étaient survenus dans un délai de 30 jours postopératoires. Des analyses séparées ont été utilisées, selon que les patients avaient été hospitalisés ou opérés en chirurgie d'un jour. La probabilité inverse de la pondération de l'exposition basée sur le score pour la propension a servi à estimer les effets ajustés de l'exposition.

Résultats La cohorte a inclus 957876 patients (583 254 patients hospitalisés et 374622 patients ambulatoires). Parmi eux, 2900 patients (0,3\%) avaient une susceptibilité à l'HM connue ou fortement suspectée. Pour les patients hospitalisés, le critère d'évaluation principal est survenu chez 146192 (25,1\%) des patients du groupe non susceptible d'HM et chez 337 (20,1\%) patients du groupe susceptible d'HM (différence de risques [DR] non ajustée : $-5,0 \%$; intervalle de confiance [IC] à $95 \%$ : $-6,9 \%$ à $-3,1 \% ; P<0,001)$. Pour les patients ambulatoires, le critère d'évaluation principal est survenu chez 9146 (2,4\%) des patients du groupe non susceptible d'HM et chez 32 (2,6\%) patients du groupe susceptible d'HM (différence de risques [DR] non ajustée : 0,2\%; IC à $95 \%:-0,7 \%$ à $1,1 \% ; P=0,72)$. Après ajustement, la susceptibilité à l'HM ne s'est pas avérée associée au critère d'évaluation principal dans le groupe de patients hospitalisés (différence de risques ajustée [DRa], 1,2\%; IC à $95 \%:-1,3 \%$ à 3,6\%; $P=0,35)$ ou dans le groupe de patients ambulatoires (DRa: -0,1\%; IC à $95 \%$ : $-1,0 \%$ à $0,9 \%$; $P=0,90$ ).

Conclusions Parmi les adultes de la province de l'Ontario ayant subi des interventions chirurgicales usuelles sous anesthésie générale entre 2009 et 2016, l'HM connue ou fortement suspectée n'a pas été associée à un plus grand risque d'évolution postopératoire défavorable. Ces constatations sont en faveur du maintien des normes des soins actuels pour la gestion des patients susceptibles d'HM.

Malignant hyperthermia (MH) is a pharmacogenetic disorder of skeletal muscle triggered in susceptible individuals by volatile anesthetics and/or succinylcholine. ${ }^{1-3}$ It manifests as a potentially lethal hypermetabolic crisis characterized by hyperkalemia, 
acidosis, and myoglobinuria and, if not treated, leads to cardiac and renal failure. ${ }^{4,5}$ The adoption of less potent volatile anesthetics has changed the pattern of $\mathrm{MH}$ clinical presentation away from fulminant to more insidious episodes, which can potentially evolve into a lifethreatening crisis. ${ }^{5,6}$ Non-triggering anesthetics, usually consisting of total intravenous anesthesia and avoidance of succinylcholine, are thought to be safe for $\mathrm{MH}$-susceptible patients. Nevertheless, $\mathrm{MH}$ reactions and adverse anesthetic reactions using trigger-free anesthetics have been reported. ${ }^{7}$ Therefore, $\mathrm{MH}$-susceptible patients may be at a higher risk of adverse postoperative outcomes after general anesthesia, due to either inadvertent administration of a triggering anesthetic agent or an $\mathrm{MH}$ response to a non-triggering anesthetic.

Because few prior studies have examined the clinical outcomes of $\mathrm{MH}$-susceptible patients after general anesthesia at a population level, there is a lingering uncertainty as to whether our current standard of care for management ensures that $\mathrm{MH}$-susceptible and non-MHsusceptible patients are experiencing similar postoperative clinical outcomes. The objective of this large, populationbased, multi-centre cohort study was to determine if patients with susceptibility to $\mathrm{MH}$ experienced similar outcomes as patients without $\mathrm{MH}$ susceptibility after surgery under general anesthesia. We hypothesized that the incidence of a composite outcome of all-cause death, hospital readmission, or major postoperative complications, all within 30 postoperative days, would not be different between $\mathrm{MH}$-susceptible and non-MHsusceptible patients.

\section{Methods}

Study design, setting, and data sources

This retrospective cohort study used administrative healthcare data from the Canadian province of Ontario and followed the STROBE $^{8}$ and RECORD $^{9}$ reporting guidelines. All residents of Ontario (population approximately 14 million) obtain healthcare services from a government-administered single-payer system. A unique, encoded identifier permitted linkage across several administrative databases, which were then analyzed at the Institute for Clinical Evaluative Sciences). Data were used from the Canadian Institute for Health Information's Discharge Abstract Database (in-hospital outcomes), National Ambulatory Care Reporting System (emergency department [ED] visits), Same Day Surgery database (CIHI-SDS), Ontario Health Insurance Plan (physician billings), Corporate Provider Database (physician demographic data from Ontario's Ministry of Health and
Long-Term Care), and Registered Persons Database (patient demographics and vital status). Ethics approval for this project was not required under Section 45 of the Ontario Personal Health Information Protection Act.

\section{Participants}

From 1 April 2009 until 31 March 2016, we identified adults (age $\geq 18 \mathrm{yr}$ ) who underwent surgeries expected to be performed under general anesthesia. We identified surgeries within the domains of neurosurgery, ears, nose, and throat, cardiac, vascular, thoracic, breast, shoulder, abdominal, pelvic, and urologic surgery using Canadian Classification of Health Intervention (CCI) codes (eTable 1, available as Electronic Supplementary Material [ESM]). Surgeries that could be performed under either general anesthesia or regional anesthesia (such as extremity surgeries) were excluded. Shoulder surgeries were included since they were likely performed under general anesthesia with or without a supplementary regional nerve block. Patients having multiple surgeries within the accrual period were only included in the cohort for their first eligible surgery.

\section{Exposure of interest}

The exposure of interest was known or strongly suspected MH susceptibility. In Ontario, this exposure is captured by a unique physician billing code (E012C) defined as a "patient who is known to have malignant hyperthermia or there is a strong suspicion of susceptibility, and the anaesthetic requires full malignant hyperthermia set up and management". A This billing code is submitted by the attending anesthesiologist and is expected to be very sensitive (i.e., capture most patients fulfilling the exposure criterion) since it results in higher remuneration for the anesthesiologist. For the primary analysis, patients were considered exposed if the billing code for $\mathrm{MH}$ was submitted on the same day as the index surgery or (to increase sensitivity) any time within the previous five years. To determine how robust the results were to this exposure definition, and to address the potential for a single anesthesiologist mistakenly or intentionally billing the E012C code for a patient not strongly suspected to be $\mathrm{MH}$ susceptible, a secondary definition of exposure was also constructed. The secondary exposure definition encompassed the primary exposure definition and at least one additional billing of the $E 012 \mathrm{C}$ code for $\mathrm{MH}$ at any

\footnotetext{
A Schedule of Benefits. Physician Services Under the Health Insurance Act (30 October 2015; effective 21 December 2015). Available from URL: http://www.health.gov.on.ca/en/pro/programs/ ohip/sob/physserv/sob_master20151221.pdf.
} 
point during the study period (i.e., before or after the index surgery). The secondary definition was considered to be less sensitive but more specific at identifying a truly $\mathrm{MH}$ susceptible patient than the primary definition.

\section{Outcomes}

The primary outcome was a composite of all-cause death, readmission to any hospital in the province, or major postoperative complications, all within 30 days of the index surgery. Secondary outcomes included the three separate components of the primary outcome, incidence of intensive care unit (ICU) admission postoperatively, hospital length of stay, and number of ED visits in Ontario within 90 days of the index surgery.

Major complications (secondary outcomes) were defined by CCI intervention codes, International Statistical Classification of Diseases-10 (ICD-10) diagnostic codes,${ }^{10}$ and/or Ontario Health Insurance Plan physician billings (eTable 2, available as ESM). Major complications were only included if they were diagnosed for the first time postoperatively. All outcomes were specified a priori.

\section{Statistical analysis}

Surgery duration is not recorded in the CIHI-SDS database, so no same-day surgery (SDS) patients in the cohort had duration of surgery data. In addition, SDS patients not admitted to hospital did not have data for hospital length of stay, intensive care unit admissions, or a significant window postoperatively in which to detect in-hospital complications. By definition, all SDS surgeries were elective. Furthermore, very few SDS patients had neuro-, thoracic, vascular, or cardiac surgery. Because of the significant differences between in- and outpatients in our cohort in terms of baseline risk, differential availability of outcome data, and our inability to adjust for surgical duration in outpatients, we elected, before analyses took place, to perform separate analyses looking at the two subcohorts (in- and outpatients) individually.

Analyses were conducted in Stata version 15 (StataCorp LLC, College Station, TX, USA). We controlled for measured confounding using inverse probability of exposure weighting (IPEW) based on propensity scores. ${ }^{11,12}$ Although matching on the propensity score is very common in the medical literature, propensity scores can reduce confounding in several other ways, including regression adjustment, stratified analyses, and IPEW. ${ }^{11}$ When using IPEW based on propensity scores, observations that were likely to be in a particular exposure group are weighted less than those that were unlikely to be in the exposure group they actually were in. IPEW results in a pseudosample where all characteristics (baseline variables and outcomes) are represented in a weighted format rather than a raw, unweighted format. Similar to propensity score matching, IPEW balances baseline variables, allowing investigators to then posit a relatively unconfounded association between exposure and outcome. Employing IPEW differs from propensity score matching by using all available data from the data set rather than eliminating observations that could not be matched. Furthermore, it may have superior statistical performance compared with matching on the propensity score. ${ }^{11}$

The propensity score was estimated using multivariable logistic regression with MH susceptibility as the dependent variable. Covariates decided upon a priori ${ }^{13}$ were considered the independent variables and included sex, age, comorbidities with a five-year look-back window (hypertension, coronary artery disease, heart failure, peripheral artery disease, diabetes, previous stroke or transient ischemic attack, chronic liver disease, cancer, chronic kidney disease, and chronic obstructive pulmonary disease), duration of the surgery (in deciles-for inpatients only), year of surgery, years since medical school graduation for the anesthesiologist, region of the province, type of hospital (academic or not), institutional surgical volume (in quintiles), whether the patient was from a rural area, the patient's median neighbourhood income quintile, whether the surgery was elective or urgent/emergent (for inpatients only), and the type of surgery performed. Observations were then weighted according to the inverse of the estimated probability of receiving the exposure that the participant actually received and analyzed using the teffects ipw package in Stata. Results were expressed as potential outcome means (which reflect the outcomes in the IPEW pseudosample),${ }^{14}$ adjusted risk differences (aRD), and adjusted relative risks. The balance of covariates pre- and post-weighting was assessed using standardized differences. ${ }^{15}$ A complete case analysis was employed as the primary analysis.

For the inpatient group, results were assessed for robustness to analytical technique by re-analyzing the primary outcome with (i) 1:1 propensity score matching using a caliper width of 0.2 of the standard deviation of the logit of the propensity score, (ii) IPEW using the secondary, more specific definition of exposure as detailed above, and (iii) multiple imputation for missing data. For the multiple imputation, we used an iterative chained equations method using a predictive mean 
matching specification for missing data in continuous variables and an ordered logit specification for missing data in ordinal variables to impute ten data sets (using Stata's $m i$ impute chained package and incorporating all covariates in the imputation model, including the primary outcome). ${ }^{16}$

To address comments raised during the peer review process, we performed a post hoc subgroup analysis to consider the potential for differential associations between the primary exposure and our main outcomes across the various included surgical procedures (i.e., effect modification by surgical procedure). In some of the surgical subgroups, zero outcome events in the MH exposure group occurred for the following outcomes (and thereby precluded subgroup analysis): all-cause death, readmission, or major complication within 30 days, as well as postoperative ICU admission. To address the problem of zero events, we considered the broader subgroups of cardiac surgeries $v s$ noncardiac surgeries to allow for all of the above outcomes to be tested. We tested for homogeneity via a joint test of interaction between the exposure and the subgroup in a logistic regression model that was weighted by the inverse probability of exposure, as determined by the propensity score. Type of surgery was removed from the propensity score model for the purposes of this subgroup analysis.

$P<0.05$ was considered statistically significant. All hypothesis tests were two sided. No corrections were made for multiple comparisons, so the comparisons of individual complications between exposure groups in inpatients were interpreted as exploratory analyses.

\section{Results}

Patients

There were 957,876 patients included in the study with 583,254 in the inpatient group (patients admitted at least one night postoperatively) and 374,622 in the outpatient group (patients discharged on the same day as surgery) (Figure). For inpatients, missing data occurred in four variables: 7,558 (1.3\%) patients were missing data on the duration of surgery, $2,322(0.40 \%)$ were missing data on median neighbourhood income quintile, $453(0.08 \%)$ were missing data on years since medical school graduation for the anesthesiologist, and fewer than six patients were missing data on rural or urban dwelling location (Figure). For outpatients, missing data occurred in five variables: $15,249(4.1 \%)$ patients were missing data on region or surgical volume at their institution, 1,409 (0.38\%) were missing data on median neighbourhood income quintile, $428(0.11 \%)$ patients were missing data on years since medical school graduation for the anesthesiologist, and fewer than six patients were missing data on rural or urban dwelling location (Figure). The total number of patients with MH susceptibility for all surgeries (i.e., not just the surgeries meeting inclusion criteria for this cohort study) in Ontario remained fairly stable from 2004 until 2015, as did the yearly number of patients in our cohort who had MH susceptibility during the study period (eFigure 1, available as ESM). Important baseline differences between the MHsusceptible and non-MH-susceptible groups were noted on several characteristics for both in- and outpatients (Table 1a and Table 1b).

\section{Unadjusted outcomes—inpatients}

The primary outcome (all-cause death, hospital readmission, or major complication within 30 days of the index surgery) occurred in 146,192 (25\%) of the inpatient non-MH-susceptible group and in 337 (20\%) of the $\mathrm{MH}-$ susceptible group (risk difference [RD], $-5.0 \% ; 95 \%$ confidence interval $[\mathrm{CI}],-6.9$ to $-3.1 \% ; P<0.001)$. Prior to any risk adjustment, $\mathrm{MH}$-susceptibility was associated with improved outcomes for major complications, intensive care unit admissions, and a shorter hospital length of stay (Table 2a).

Adjusted outcomes—inpatients

After adjustment, being MH susceptible was not significantly associated with any of the outcomes, including the primary outcome (aRD 1.2\%; 95\% CI, -1.3 to $3.6 \% ; P=0.35$ ) (Table $2 a$ ).

Unadjusted outcomes—outpatients

The primary outcome occurred in $9,146(2.4 \%)$ of the outpatient non-MH-susceptible group and in $32(2.6 \%)$ of the MH-susceptible group (RD, $0.2 \% ; 95 \% \mathrm{CI},-0.7$ to $1.1 \% ; P=0.72$ ). Being $\mathrm{MH}$ susceptible was associated with more ED visits (Table 2b).

Adjusted outcomes—outpatients

After adjustment, being MH susceptible was not associated with the primary outcome (aRD, $-0.1 \%$; $95 \% \mathrm{CI},-1.0$ to $0.9 \% ; P=0.90$ ) (Table 2b). Nevertheless, it was associated with an increased incidence of any ED visit (aRD, 3.6\%; $95 \% \mathrm{CI}, 0.9$ to $6.2 \% ; P=0.008$ ) and an increased absolute number of ED visits (aRD, 0.08 visits; $95 \%$ CI, 0.02 to 0.13 visits; $P=0.010$ ).

Exploratory outcomes-inpatients

After adjustment in exploratory analyses, $\mathrm{MH}$ susceptibility was not statistically significantly associated 


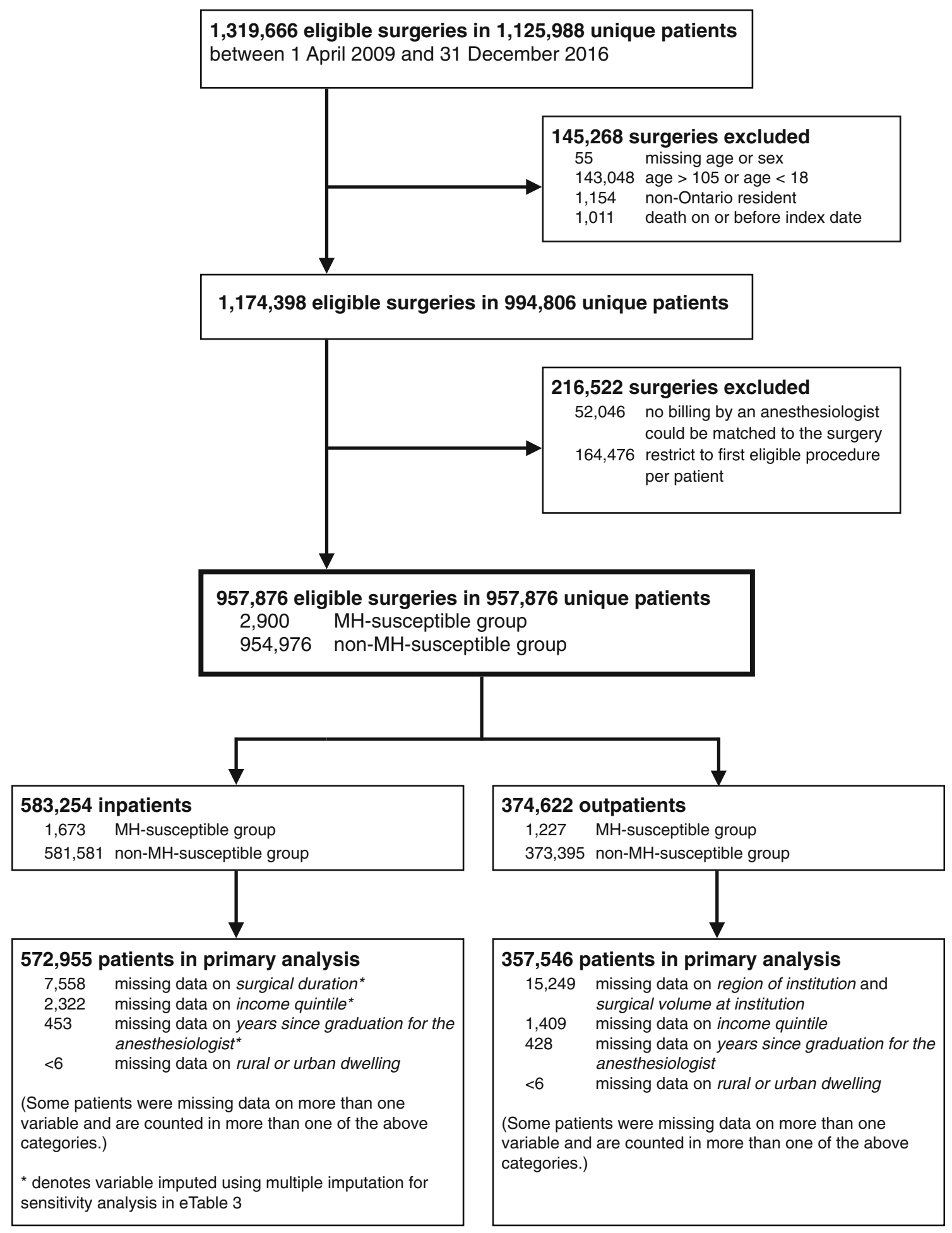

Figure Flow diagram of cohort build and missing data 


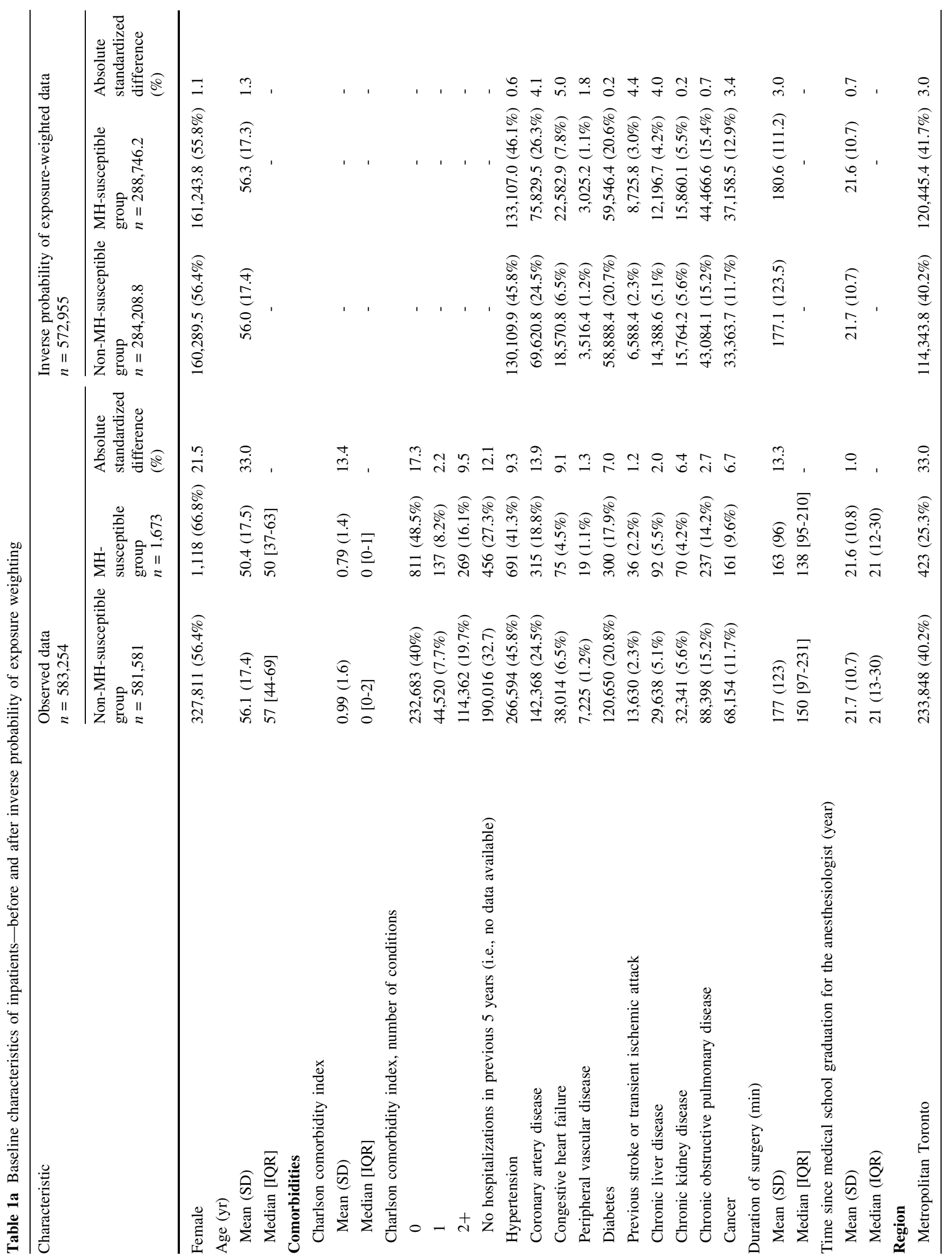




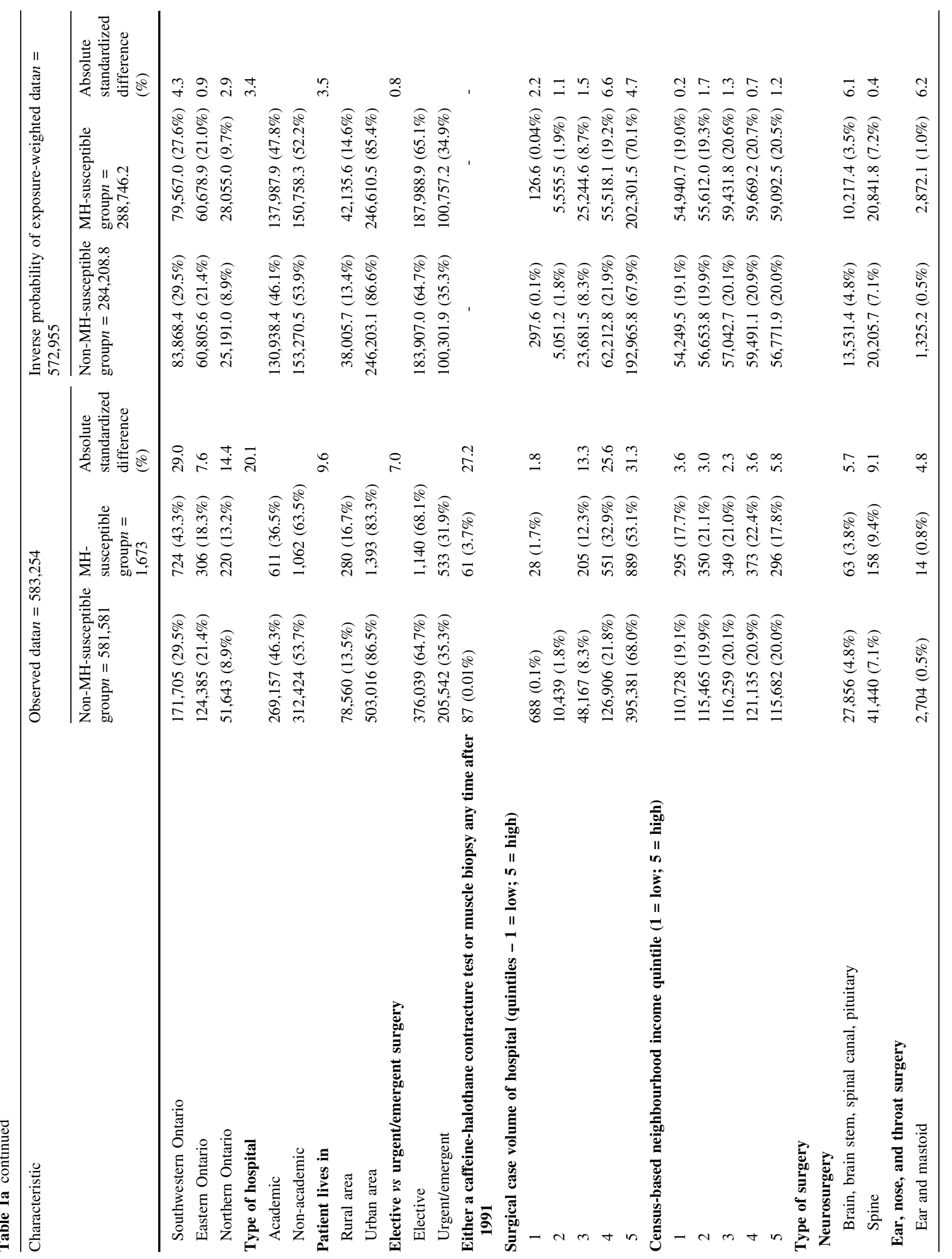




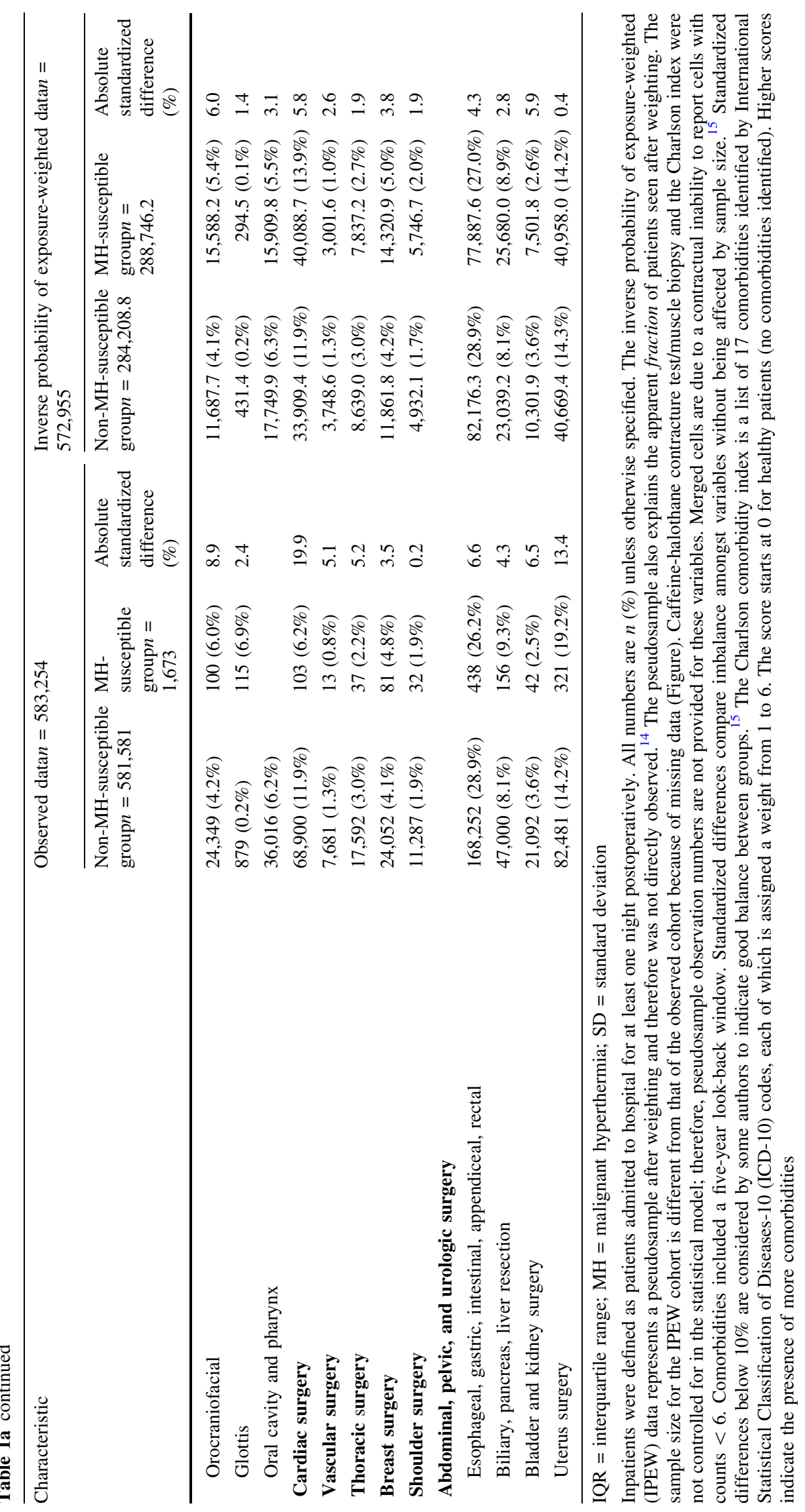




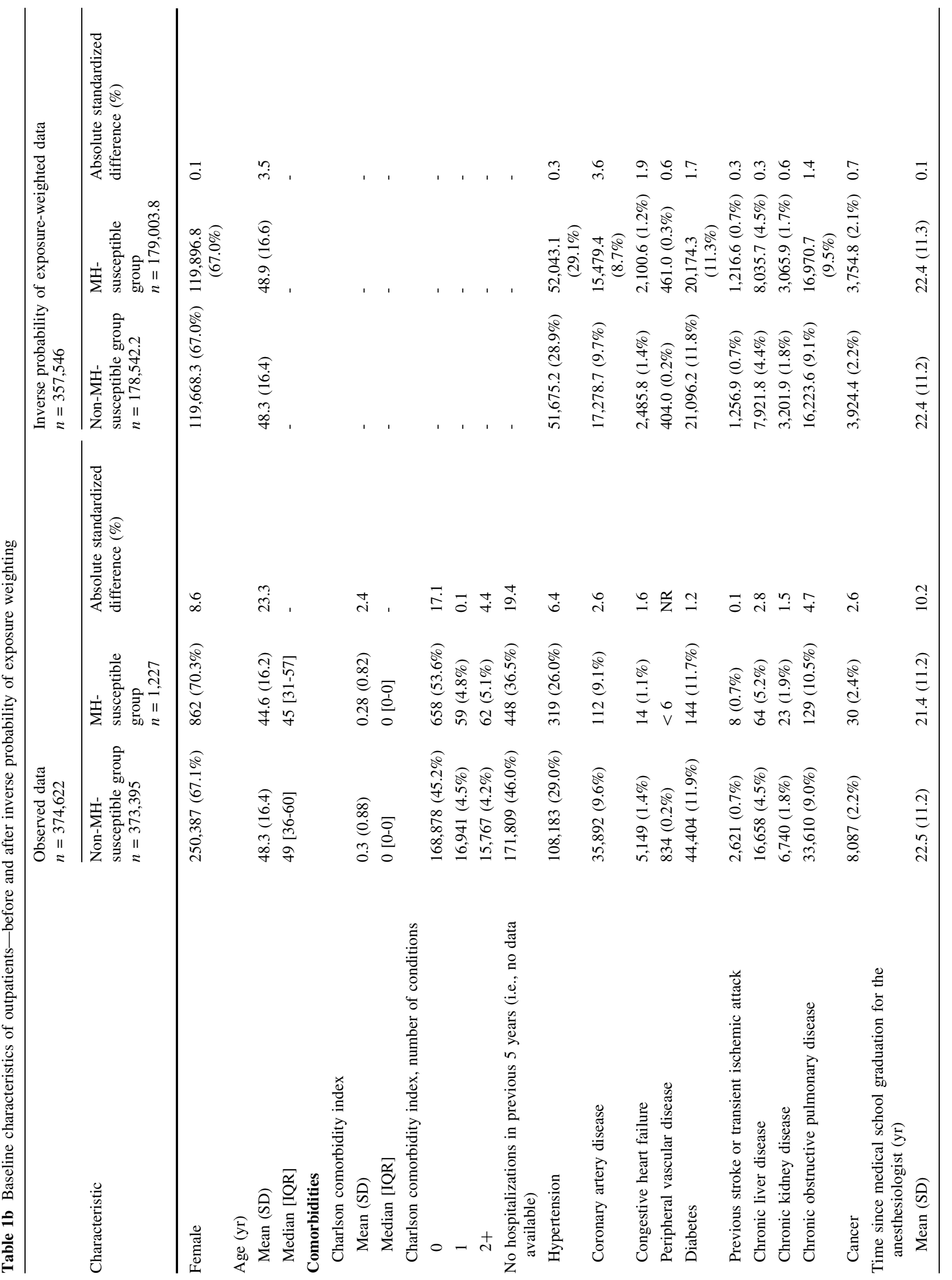




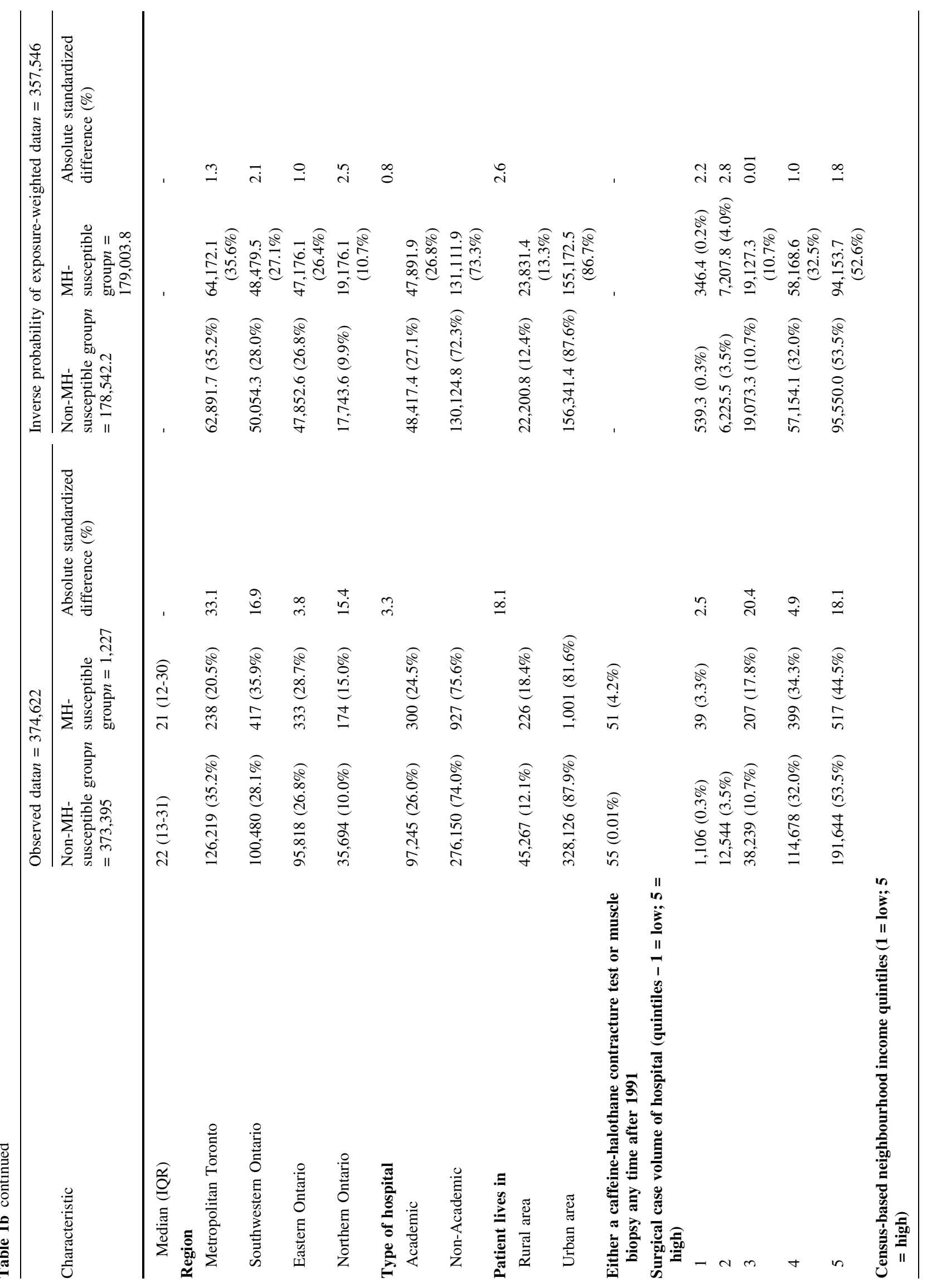




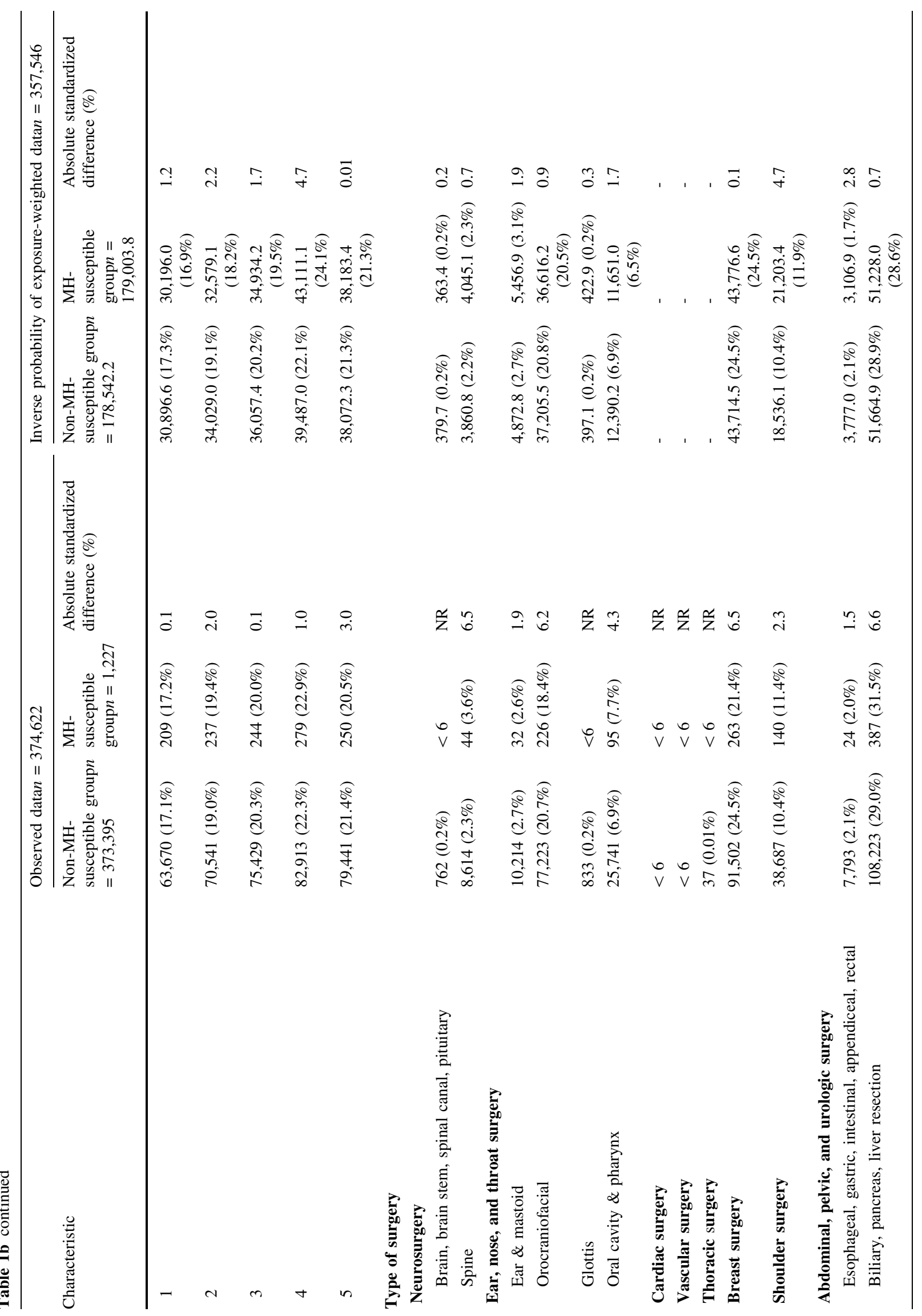




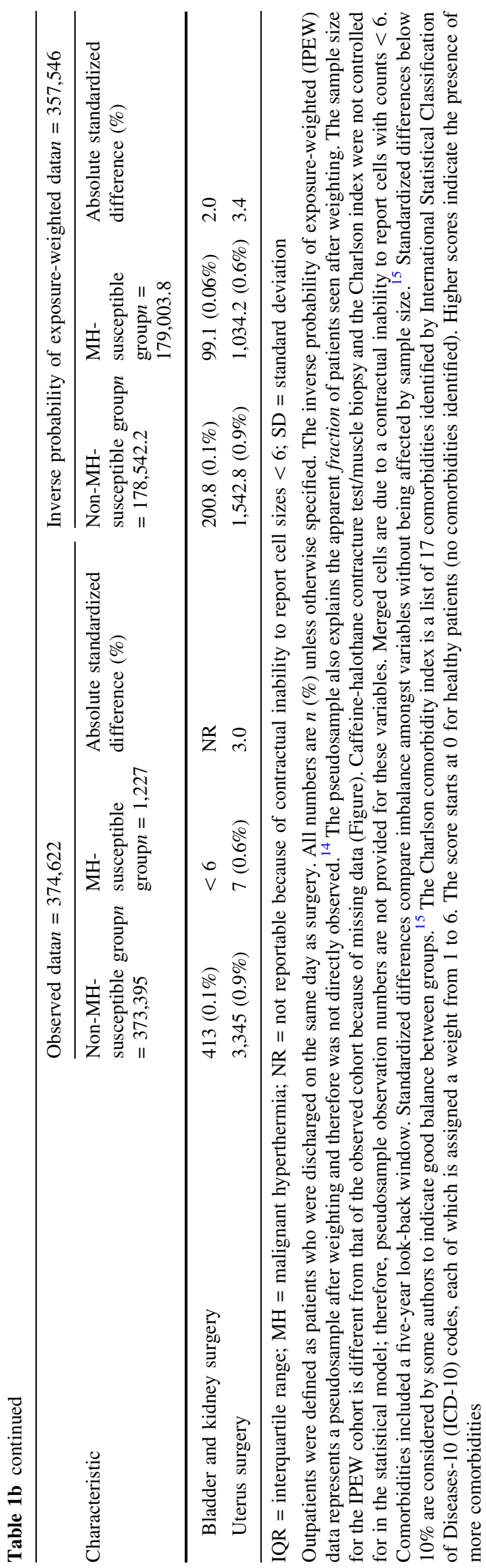

with any major postoperative complications in inpatients (Table 3).

Sensitivity analyses

Across multiple sensitivity analyses, similar point estimates and $95 \%$ CIs for the primary outcome in inpatients were found (eTable 3). Propensity score matching (aRD, $-0.4 \%$; $95 \% \mathrm{CI},-3.2$ to $2.4 \% ; P=$ 0.79) using an alternative definition of the exposure variable (aRD, $-0.6 \% ; 95 \% \mathrm{CI},-5.7$ to $4.5 \% ; P=0.83$ ) and accounting for missing data using multiple imputation (aRD, $0.8 \%$; 95\% CI, -1.6 to $3.2 \% ; P=0.50$ ) resulted in findings congruent with the primary analysis.

Subgroup analyses (post hoc analyses)

Subgroup analysis for the primary outcome (eTable 4, available as ESM) did not show significant heterogeneity amongst surgical subgroups. Similarly, analyzing subgroups by cardiac or non-cardiac surgery also did not show significant heterogeneity (eTable 5, available as ESM). Due to the low numbers of events, confidence intervals within most subgroups were wide.

\section{Discussion}

In this large population-based study, we did not find any clinically important or statistically significant association between MH susceptibility and adverse postoperative outcomes in either in- or outpatients. Although outpatients had a significant association with both any postoperative ED visit and the absolute number of postoperative ED visits, this effect was small in magnitude and of uncertain clinical importance. It may have been that, due to an abundance of caution and a fear of an $\mathrm{MH}$ reaction, $\mathrm{MH}$-susceptible same-day surgery patients were warned by numerous perioperative health professionals to return to the ED if anything untoward happened postoperatively. Since patients are not experts in $\mathrm{MH}$, they may have gone to the ED for problems non-MHsusceptible patients would not have considered serious enough to warrant an ED visit such as postoperative nausea and vomiting, pain, or a fever of unknown cause.

This study was not carried out with a non-inferiority design. Nevertheless, the upper extent of the $95 \%$ CI for the relative risk of the primary outcome was 1.15 , which many researchers would plausibly interpret as excluding most clinically relevant increased risks. ${ }^{17}$

Although a care-neutral effect of administering a nontriggering general anesthetic to $\mathrm{MH}$-susceptible patients has been assumed by most clinicians, no previous 
Table 2a Outcomes for inpatients

\begin{tabular}{|c|c|c|c|c|c|c|c|c|}
\hline \multirow[b]{2}{*}{ Outcome } & \multicolumn{4}{|c|}{ Unadjusted values } & \multicolumn{4}{|l|}{ Adjusted values } \\
\hline & $\begin{array}{l}\text { Non-MH- } \\
\text { susceptible } \\
\text { group } \\
n=581,581\end{array}$ & $\begin{array}{l}\text { MH- } \\
\text { susceptible } \\
\text { group } \\
n=1,673\end{array}$ & $\begin{array}{l}\text { Unadjusted } \\
\text { risk } \\
\text { difference } \\
(95 \% \mathrm{CI}) \\
n=583,254\end{array}$ & $\begin{array}{l}\text { Unadjusted } \\
\text { relative risk } \\
\text { (for binary } \\
\text { outcomes) } \\
(95 \% \mathrm{CI}) \\
n=583,254\end{array}$ & $\begin{array}{l}\text { Non-MH- } \\
\text { susceptible } \\
\text { group potential } \\
\text { outcome mean } \\
(95 \% \mathrm{CI}) \\
n=284,208.8\end{array}$ & $\begin{array}{l}\text { MH- } \\
\text { susceptible } \\
\text { group } \\
\text { potential } \\
\text { outcome mean } \\
(95 \% \mathrm{CI}) \\
n=288,746.2\end{array}$ & $\begin{array}{l}\text { Adjusted } \\
\text { risk } \\
\text { difference } \\
(95 \% \mathrm{CI}) \\
n= \\
\quad 572,955\end{array}$ & $\begin{array}{l}\text { Adjusted } \\
\text { relative risk } \\
\text { (for binary } \\
\text { outcomes) } \\
(95 \% \text { CI) } \\
n=572,955\end{array}$ \\
\hline \multirow{3}{*}{$\begin{array}{l}\text { Primary outcome of all- } \\
\text { cause death, hospital } \\
\text { readmission, or major } \\
\text { complication within } \\
30 \text { days }\end{array}$} & 146,192 & 337 & $-5.0 \%$ & 0.80 & $25.0 \%$ & $26.2 \%$ & $1.2 \%$ & 1.05 \\
\hline & $(25.1 \%)$ & $(20.1 \%)$ & $\begin{array}{l}(-6.9 \text { to } \\
-3.1 \%)\end{array}$ & $(0.73$ to 0.88$)$ & ( 24.9 to $25.1 \%$ ) & $\begin{array}{l}(23.7 \text { to } \\
28.7 \%)\end{array}$ & $\begin{array}{r}(-1.3 \text { to } \\
3.6 \%)\end{array}$ & (0.95 to 1.15$)$ \\
\hline & & & $P<0.001$ & & & & $P=0.35$ & \\
\hline \multirow{3}{*}{$\begin{array}{l}\text { All-cause death within } \\
30 \text { days }\end{array}$} & 11,037 & 23 & $-0.5 \%$ & 0.72 & $1.9 \%$ & $2.3 \%$ & $0.4 \%$ & 1.21 \\
\hline & $(1.9 \%)$ & $(1.4 \%)$ & $\begin{array}{l}(-1.1 \text { to } \\
0.04 \%)\end{array}$ & (0.48 to 1.09$)$ & (1.8 to $1.9 \%)$ & $(1.2$ to $3.4 \%)$ & $\begin{array}{r}(-0.7 \text { to } \\
1.5 \%)\end{array}$ & (0.74 to 1.98$)$ \\
\hline & & & $P=0.12$ & & & & $P=0.48$ & \\
\hline \multirow{3}{*}{$\begin{array}{l}\text { Readmission within } 30 \\
\text { days }\end{array}$} & 35,039 & 95 & $-0.3 \%$ & 0.94 & $6.0 \%$ & $6.9 \%$ & $0.9 \%$ & 1.14 \\
\hline & $(6.0 \%)$ & $(5.7 \%)$ & $\begin{array}{r}(-1.5 \text { to } \\
0.8 \%)\end{array}$ & (0.78 to 1.15$)$ & $(6.0$ to $6.1 \%)$ & $(5.2$ to $8.5 \%)$ & $\begin{array}{r}(-0.8 \text { to } \\
2.5 \%)\end{array}$ & (0.90 to 1.45$)$ \\
\hline & & & $P=0.55$ & & & & $P=0.31$ & \\
\hline \multirow{3}{*}{$\begin{array}{l}\text { Major complication } \\
\text { within } 30 \text { days }\end{array}$} & 118,718 & 262 & $-4.8 \%$ & 0.77 & $20.3 \%$ & $21.0 \%$ & $0.7 \%$ & 1.03 \\
\hline & $(20.4 \%)$ & $(15.7 \%)$ & $\begin{array}{l}(-6.5 \text { to } \\
-3.0 \%)\end{array}$ & (0.69 to 0.86$)$ & (20.2 to $20.4 \%$ ) & $\begin{array}{l}(18.7 \text { to } \\
23.3 \%)\end{array}$ & $\begin{array}{r}(-1.6 \text { to } \\
3.0 \%)\end{array}$ & (0.93 to 1.16 ) \\
\hline & & & $P<0.001$ & & & & $P=0.56$ & \\
\hline \multirow{3}{*}{$\begin{array}{l}\text { Intensive care unit } \\
\text { admission }\end{array}$} & 127,842 & 274 & $-5.6 \%$ & 0.75 & $22.0 \%$ & 24.0 & $2.0 \%$ & 1.09 \\
\hline & $(22.0 \%)$ & $(16.4 \%)$ & $\begin{array}{l}(-7.4 \text { to } \\
-3.8 \%)\end{array}$ & (0.67 to 0.83$)$ & (21.9 to $22.1 \%$ ) & $\begin{array}{l}\text { (21.9 to } \\
26.0 \%)\end{array}$ & $\begin{array}{r}(-0.1 \text { to } \\
4.0 \%)\end{array}$ & (1.0 to 1.19$)$ \\
\hline & & & $P<0.001$ & & & & $P=0.063$ & \\
\hline \multicolumn{9}{|l|}{$\begin{array}{l}\text { Hospital length of stay } \\
\text { (days) }\end{array}$} \\
\hline \multirow[t]{2}{*}{ Mean (SD) } & 7.3 & 6.0 & -1.3 days & - & 7.3 days & 7.1 days & -0.2 days & - \\
\hline & $(14.1)$ & $(10.9)$ & $\begin{array}{l}(-2.0 \text { to } \\
\quad-0.7 \\
\quad \text { days }) \\
P<0.001\end{array}$ & & (7.2 to 7.3 ) & (6.5 to 7.7$)$ & $\begin{array}{l}(-0.8 \text { to } \\
0.5) \\
P=0.61\end{array}$ & \\
\hline Median [IQR] & $4[2-8]$ & $3[1-6]$ & - & - & - & - & - & - \\
\hline \multicolumn{9}{|l|}{$\begin{array}{l}\text { Emergency department } \\
\text { visits in Ontario } \\
\text { within } 90 \text { days of the } \\
\text { index surgery }\end{array}$} \\
\hline \multirow[t]{3}{*}{ Mean (SD) } & $0.46(1.1)$ & $0.48(1.1)$ & 0.01 visits & - & 0.46 visits & 0.50 visits & 0.04 visits & - \\
\hline & & & $\begin{array}{c}(-0.04 \text { to } \\
0.07)\end{array}$ & & $(0.46$ to 0.46$)$ & $(0.43$ to 0.57$)$ & $\begin{array}{c}(-0.03 \text { to } \\
0.11)\end{array}$ & \\
\hline & & & $P=0.60$ & & & & $P=0.27$ & \\
\hline Median [IQR] & $0[0-1]$ & $0[0-1]$ & - & - & - & - & - & - \\
\hline
\end{tabular}


Table 2a continued

\begin{tabular}{|c|c|c|c|c|c|c|c|c|}
\hline \multirow[b]{2}{*}{ Outcome } & \multicolumn{4}{|c|}{ Unadjusted values } & \multicolumn{4}{|l|}{ Adjusted values } \\
\hline & $\begin{array}{l}\text { Non-MH- } \\
\text { susceptible } \\
\text { group } n= \\
581,581\end{array}$ & $\begin{array}{l}\text { MH- } \\
\text { susceptible } \\
\text { group } n= \\
1,673\end{array}$ & $\begin{array}{l}\text { Unadjusted } \\
\text { risk } \\
\text { difference } \\
(95 \% \mathrm{CI}) n \\
=583,254\end{array}$ & $\begin{array}{l}\text { Unadjusted } \\
\text { relative risk } \\
\text { (for binary } \\
\text { outcomes) } \\
(95 \% \mathrm{CI}) n= \\
583,254\end{array}$ & $\begin{array}{l}\text { Non-MH- } \\
\text { susceptible } \\
\text { group potential } \\
\text { outcome mean } \\
(95 \% \mathrm{CI}) n= \\
284,208.8\end{array}$ & $\begin{array}{l}\text { MH- } \\
\text { susceptible } \\
\text { group } \\
\text { potential } \\
\text { outcome mean } \\
(95 \% \mathrm{CI}) n= \\
288,746.2\end{array}$ & $\begin{array}{l}\text { Adjusted } \\
\text { risk } \\
\text { difference } \\
(95 \% \mathrm{CI}) n \\
=572,955\end{array}$ & $\begin{array}{l}\text { Adjusted } \\
\text { relative risk } \\
\text { (for binary } \\
\text { outcomes) } \\
(95 \% \mathrm{CI}) n= \\
572,955\end{array}$ \\
\hline \multirow[t]{2}{*}{$\begin{array}{l}\text { Any ED visit within } 90 \\
\text { days of the index } \\
\text { surgery }\end{array}$} & $\begin{array}{l}157,591 \\
(27.1 \%)\end{array}$ & $\begin{array}{l}464 \\
(27.7 \%)\end{array}$ & $\begin{array}{l}0.6 \% \\
(-1.5 \text { to } \\
2.8 \%)\end{array}$ & $\begin{array}{l}1.02 \\
(0.95 \text { to } 1.11)\end{array}$ & $\begin{array}{l}27.1 \% \\
\text { (26.9 to } 27.2 \% \text { ) }\end{array}$ & $\begin{array}{l}28.3 \% \\
(25.6 \text { to } \\
31.1 \%)\end{array}$ & $\begin{array}{l}1.3 \% \\
(-1.4 \text { to } \\
4.0 \%)\end{array}$ & \multirow[t]{2}{*}{$\begin{array}{l}1.05 \\
(0.95 \text { to } 1.15)\end{array}$} \\
\hline & & & $P=0.56$ & & & & $P=0.35$ & \\
\hline
\end{tabular}

$\mathrm{CI}=$ confidence interval; $\mathrm{IQR}=$ interquartile range; $\mathrm{MH}=$ malignant hyperthermia; $\mathrm{SD}=$ standard deviation

Inpatients were defined as patients admitted to hospital for at least one night postoperatively. Data are $n$ (\%) or percent (95\% CI) unless otherwise stated. Outcomes for the three components of the composite primary outcome were not mutually exclusive. Therefore, the sum of the events in the components is greater than the composite event rate. Diagnostic and intervention codes used to define outcomes are specified in eTable 2 in the online-only supplement. Complete case analysis resulted in some missing data (Figure). Adjusted results obtained from inverse probability of exposure weighting based on propensity scores. The propensity score was estimated using multivariable logistic regression with known or strongly suspected $\mathrm{MH}$ as the dependent variable and a vector of covariates decided upon a priori as the independent variables (sex, age, comorbidities with a five-year look-back window [hypertension, coronary artery disease, heart failure, peripheral artery disease, diabetes, previous stroke or transient ischemic attack, chronic liver disease, cancer, chronic kidney disease, and chronic obstructive pulmonary disease], duration of the surgery [in deciles], fiscal year of surgery, years since medical school graduation for the anesthesiologist, region of the province, type of hospital [academic or not], institutional surgical volume [in quintiles], whether the patient was from a rural area, the patient's income quintile, whether the surgery was elective or urgent/emergent, and the type of surgery performed). Risk differences and relative risks are for the $\mathrm{MH}$-susceptible group relative to the non-MH-susceptible group. For example, the risk difference for the primary outcome of $1.2 \%$ (95\% CI, -1.3 to $3.6 \%$ means that the MH-susceptible group had a non-statistically significant $1.2 \%$ absolute increase of all-cause death, hospital readmission, or major complication within 30 days compared with the non-MH-susceptible group. Potential outcome means reflect the outcomes in the inverse probability of exposure-weighted pseudosample (i.e., post-adjustment) and therefore were not directly observed outcomes ${ }^{14}$

population-based study had actually shown this care neutrality. These results now permit clinicians to confidently state to their MH-susceptible patients that a non-triggering general anesthetic will not, on average, increase the perioperative risk of adverse outcomes.

Due to the low number of events occurring for many of the outcomes, it is likely that the subgroups examined are at risk of being underpowered. Nonetheless, we did not find statistical evidence of heterogeneity amongst the surgical subgroups examined.

One strength of this study is its large sample of patients, representing a wide variety of surgeries at many hospitals. Many outcome events occurred for most variables, increasing the statistical power to detect important differences. Since this was a population-based study based in the largest Canadian province, patients in this cohort are likely representative of other Canadians in terms of sex, age, socioeconomic groups, comorbidity distributions, and other important prognostic factors. Another strength of this study is that the principal findings were congruent across multiple sensitivity analyses using propensity score matching (rather than IPEW), a more specific definition of the exposure, and after accounting for missing data using multiple imputation.

This study has several limitations. Since the exposure of MH susceptibility was determined using a billing code, there was a risk of misclassification if the code was not billed as described in the provincial Schedule of Benefits. International Statistical Classification of Diseases-10 diagnostic codes may not have captured all adverse postoperative outcomes. The anesthesiologist's career experience was controlled for but the career experience of the surgeon was not. We did not identify or adjust for surgical cases where a handover of anesthesiologist occurred intraoperatively. ${ }^{18}$ We studied only patients 18 yr and older and therefore our results do not necessarily 


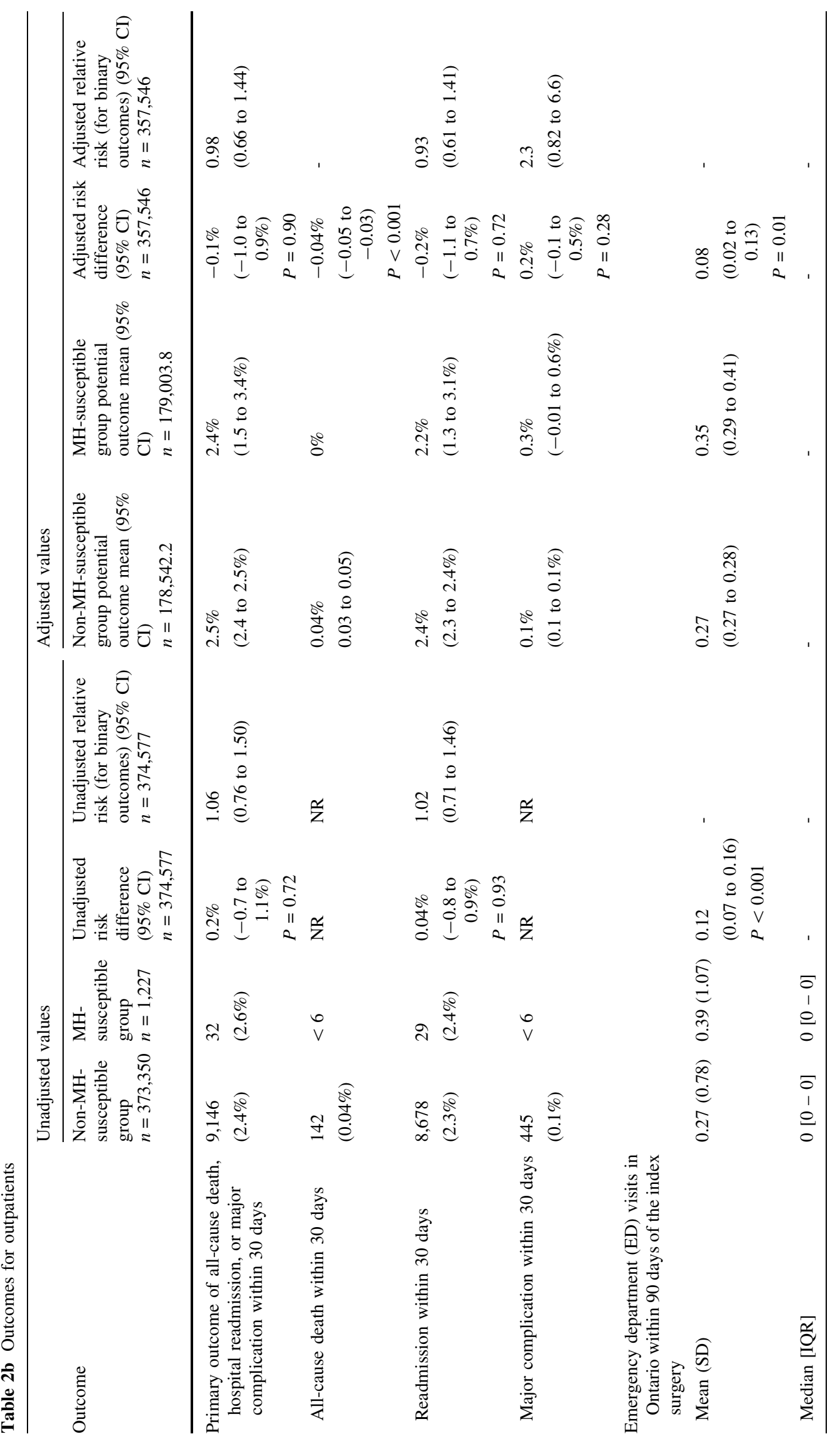




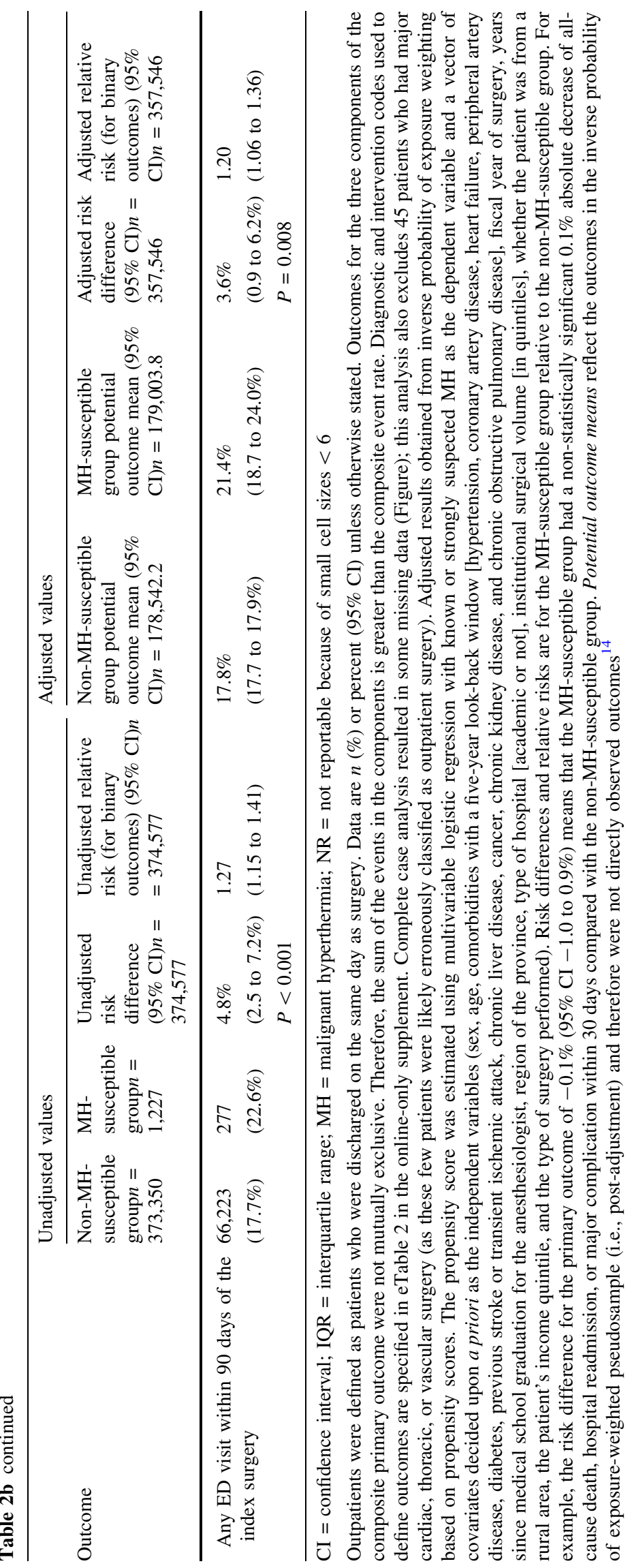




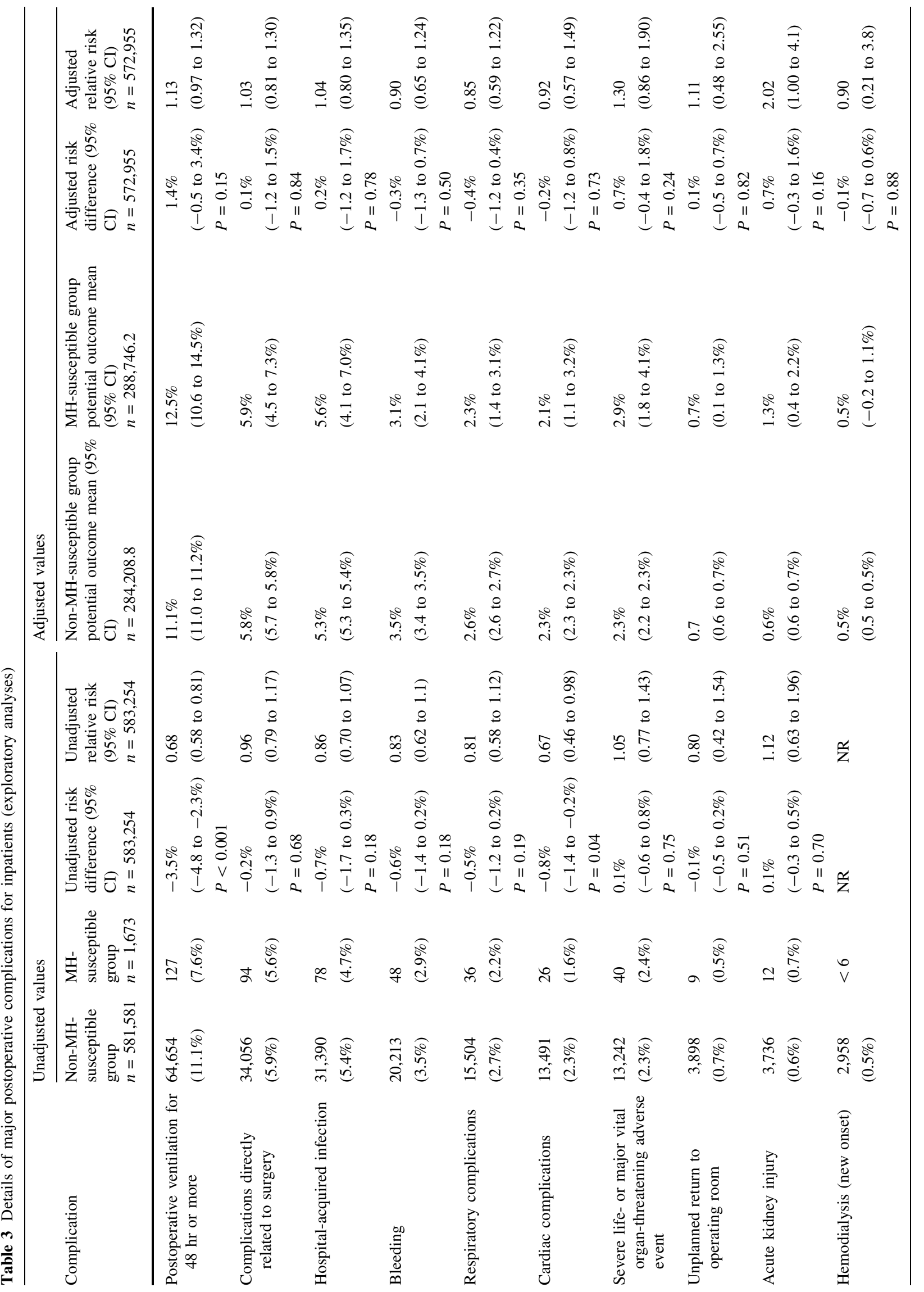




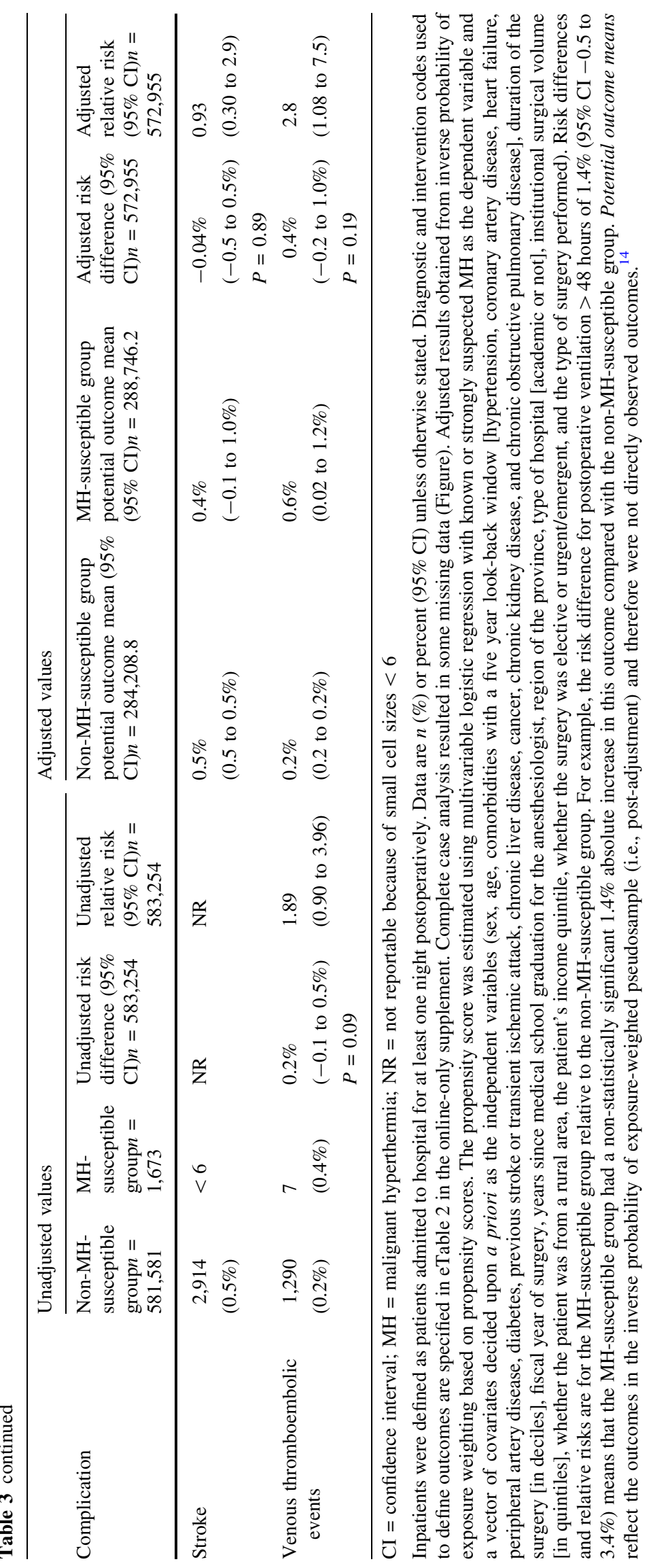


apply to patients younger than 18. Actual MH clinical reactions were not evaluated specifically in this study and we do not know if any of the patients in the cohort had physical manifestations of $\mathrm{MH}$. All observational studies will have residual confounding from unmeasured or unknown confounders. Although we have attempted to reduce confounding as much as possible, our results reflect associations only. These associations may be biased by residual confounding.

\section{Conclusions}

Among adults in Ontario who underwent common surgeries under general anesthesia from 2009 to 2016, known or suspected MH susceptibility was not associated with higher risk of adverse postoperative outcomes at the population level. These findings support the current standard of care management for $\mathrm{MH}$-susceptible patients.

Acknowledgements The data were analyzed by Britney Allen, MSc (Biostatistician at ICES Western), and Philip Jones, MD MSc, both of whom had full access to all the data in the study and take responsibility for the integrity of the data and the accuracy of the data analysis. Duminda N. Wijeysundera is supported in part by a New Investigator Award from the Canadian Institutes of Health Research. DNW and SR are both supported in part by a Merit Award from the Department of Anesthesia at the University of Toronto.

Conflicts of interest None of the authors have any conflicts of interest to declare.

Editorial responsibility This submission was handled by Dr. Hilary P. Grocott, Editor-in-Chief, Canadian Journal of Anesthesia.

Author contributions All authors contributed substantially to the study's conception, design, interpretation of data, and drafting the article. Philip M. Jones, Britney N. Allen, Salimah Z. Shariff, Krista $M$. Bray Jenkyn, and Duminda $N$. Wijeysundera contributed substantially to data acquisition and analysis.

Funding/Support This study was supported by the Department of Anesthesia \& Perioperative Medicine at the University of Western Ontario. This project was conducted at the Institute for Clinical Evaluative Sciences (ICES) Western Site. ICES is funded by annual grants from the Ontario Ministry of Health and Long-term Care (MOHLTC). Core funding for ICES Western is provided by the Academic Medical Organization of Southwestern Ontario (AMOSO), the Schulich School of Medicine and Dentistry (SSMD), The University of Western Ontario, and the Lawson Health Research Institute (LHRI). The opinions, results, and conclusions are those of the authors and are independent from the funding sources. No endorsement by ICES, AMOSO, SSMD, LHRI, or the MOHLTC is intended or should be inferred. Parts of this material are based on data and information compiled and provided by the Canadian Institute for Health Information (CIHI). The analyses, conclusions, opinions, and statements expressed in the material are those of the authors and not necessarily those of CIHI.
Role of the sponsors statement Neither the ICES nor the Ontario MOHLTC had a role in the design and conduct of the study; collection, management, analysis, and interpretation of the data; preparation, review, or approval of the manuscript; or decision to submit the manuscript for publication.

\section{References}

1. Riazi S, Kraeva N, Hopkins PM. Updated guide for the management of malignant hyperthermia. Can J Anesth 2018; 65: 709-21.

2. Santos JM, Andrade PV, Galleni L, et al. Idiopathic hyperCKemia and malignant hyperthermia susceptibility. Can J Anesth 2017; 64: 1202-10.

3. Kraeva N, Sapa A, Dowling JJ, Riazi S. Malignant hyperthermia susceptibility in patients with exertional rhabdomyolysis: a retrospective cohort study and updated systematic review. Can J Anesth 2017; 64: 736-43.

4. MacLennan DH, Zvaritch E. Mechanistic models for muscle diseases and disorders originating in the sarcoplasmic reticulum. Biochim Biophys Acta 2011; 1813: 948-64.

5. Riazi S, Larach $M G, H u C$, Wijeysundera D, Massey $C$, Kraeva $N$. Malignant hyperthermia in Canada: characteristics of index anesthetics in 129 malignant hyperthermia susceptible probands. Anesth Analg 2014; 118: 381-7.

6. Larach MG, Gronert GA, Allen GC, Brandom BW, Lehman EB. Clinical presentation, treatment, and complications of malignant hyperthermia in North America from 1987 to 2006. Anesth Analg 2010; 110: 498-507.

7. Brandom BW, Muldoon SM. Unexpected MH deaths without exposure to inhalation anesthetics in pediatric patients. Paediatr Anaesth 2013; 23: 851-4.

8. Vandenbroucke JP, von Elm E, Altman DG, et al. Strengthening the Reporting of Observational Studies in Epidemiology (STROBE): explanation and elaboration. PLoS Med 2007; 4: e297.

9. Benchimol EI, Smeeth L, Guttmann A, et al. The REporting of studies Conducted using Observational Routinely-collected health Data (RECORD) statement. PLoS Med 2015; 12: e1001885.

10. Southern DA, Burnand B, Droesler SE, et al. Deriving ICD-10 codes for patient safety indicators for large-scale surveillance using administrative hospital data. Med Care 2017; 55: 252-60.

11. Austin $P C$. The performance of different propensity-score methods for estimating differences in proportions (risk differences or absolute risk reductions) in observational studies. Stat Med 2010; 29: 2137-48.

12. Haukoos JS, Lewis RJ. The propensity score. JAMA 2015; 314 : 1637-8.

13. Thorpe KE. How to construct regression models for observational studies (and how NOT to do it!). Can J Anesth 2017; 64: 461-70.

14. Ukoumunne OC, Williamson E, Forbes AB, Gulliford MC, Carlin $J B$. Confounder-adjusted estimates of the risk difference using propensity score-based weighting. Stat Med 2010; 29: 3126-36.

15. Austin PC, Stuart EA. Moving towards best practice when using inverse probability of treatment weighting (IPTW) using the propensity score to estimate causal treatment effects in observational studies. Stat Med 2015; 34: 3661-79. 
16. Sterne JA, White IR, Carlin JB, et al. Multiple imputation for missing data in epidemiological and clinical research: potential and pitfalls. BMJ 2009; 338: b2393.

17. Yusuf S, Collins R, Peto R. Why do we need some large, simple randomized trials? Stat Med 1984; 3: 409-22.
18. Jones PM, Cherry RA, Allen BN, et al. Association between handover of anesthesia care and adverse postoperative outcomes among patients undergoing major surgery. JAMA 2018; 319: 143-53. 